tests identified a subgroup of 85 patients at very low risk $(1 \%$ mortality).

Is identification of a potential for ventricular tachycardia in the convalescent phase of myocardial infarction of any practical clinical importance? The answer at present must be no. Unless a randomised controlled trial of treatment with antiarrhythmic drugs in electrically unstable patients is shown to improve their prognosis the procedure is of academic interest only. Even if the results of such a trial were positive the use of an uncomfortable, potentially hazardous procedure requiring highly trained personnel is clearly impracticable for screening. Alternative noninvasive methods of preliminary screening can identify patients at high risk of sudden arrhythmic death. The most promising techniques are ambulatory electrocardiography, determination of the ejection fraction by radionuclide ventriculography, ${ }^{9}$ and recording areas of delayed ventricular activation ("late potentials") from highly amplified, signal averaged electrocardiograms. ${ }^{22}$ Once these techniques have been applied patients identified as at high risk might then be candidates for electrophysiological testing to determine effective treatment and to exclude drug related proarrhythmic effects.

STUART M COBBE

Walton Professor of Medical Cardiology,

Royal Infirmary,

Glasgow G31 2ER

I Norris RM, Barnaby PF, Brandt PWT, et al. Prognosis after recovery from first acute myocardial infarction: determinants of reinfarction and sudden death. Am J Cardiol 1984;53:408-13. Taylor GJ, Humphries JO, Mellits ED, et al. Predictors of clinical course: coronary anatomy and left ventricular function after recovery from acute myocardial infarction. Circulation 1980;62: $960-70$
3 Mukharii J, Rude RE, Poole WK, et al. Risk factors for sudden death following acute myocardial infarction (two year follow-up). Am f Cardiol 1984;54:31-6.

4 Ruberman W, Weinblatt E, Goldberg JD, Frank CW, Chaudhary BS, Shapiro S. Ventricular premature complexes and sudden death after myocardial infarction. Circulation 1981;64 297-305.

Theroux P, Waters DD, Halphen C, Debaisieux JC, Mizgala HF. Prognostic value of exercise testing soon after myocardial infarction. N Engl f Med 1979;301:341-5.

6 Weld FM, Chu KL, Bigger JT, Rolnitzky LM. Risk stratification with low-level exercise testing 2 weeks after acute myocardial infarction. Circulation 1981;64:306-14.

7 Moss AJ, Davis HT, Decamilla J, Bayer LW. Ventricular ectopic beats and their relation to sudden and non-sudden cardiac death after myocardial infarction. Circulation 1979;60: 998-1003.

8 Schulze RA Jr, Strauss HW, Pitt B. Sudden death in the year following myocardial infarction: relation to ventricular premature contractions in the late hospital phase and left ventricular relation to ventricular premature contractions

9 Bigger JT, Fleiss JL, Kleiger R, Miller JP, Rolnitsky LM, Multicenter Post-Infarction Group. The relationship between ventricular arrhythmias, left ventricular dysfunction and mortality in the 2 years after myocardial infarction. Circulation 1984;69:250-8.

10 Bigger JT, Weld FM, Rolnitsky LM. Prevalence characteristics and significance of ventricular tachycardia (three or more complexes) detected with ambulatory electrocardiographic recording in the late hospital phase of acute myocardial infarction. Am $\mathcal{J}$ Cardiol. 1981;48:815-23.

11 Chamberlain DA, Jewitt DE, Julian DG, et al. Oral mexiletine in high risk patients after myocardial infarction. Lancet 1980;ii:1324-7.

12 Van Durme JP, Hagenmeijer F, Bogaert M, et al. Chronic antidysrhythmic therapy after myocardial infarction. Design of Gent-Rotterdam aprindine study. In: Boissel JP, Kumt CR, eds. Multicenter controlled trials: principles and practice. Paris: Inserm, 1977:43.

13 Velebit V, Podrid P, Lown B, Cohen BH, Graboys TB. Agravation and provocation of ventricular arrhythmias by antiarrhythmic drugs. Circulation 1982;65:886-93.

14 Horowitz LN, Josephson ME, Kastor JA. Intracardiac electrophysiologic studies as a method for the optimization of drug theraphy in chronic ventricular arrhythmia. Prog Cardiovasc Dis 1980;23:81-9.

15 Poser RF, Podrid PJ, Lombardi F, Lown B. Aggravation of arrhythmia induced with antiarrhythmic drugs during electrophysiologic testing. Am Heart f 1985;110:9-16.

16 Swerdlow CD, Winkle RA, Mason JW. Determinants of survival in patients with ventricular tachycardia. N Engl F Med 1983;308: 1436-42.

17 Greene HL, Reid PR, Schaeffer AH. The repetitive ventricular response in man. A predictor of sudden death. N Engl J Med 1978;299:730-4.

18 Hamer A, Vohra J, Hunt D, Sloman G. Prediction of sudden death by electrophysiological studies in high risk patients surviving acute myocardial infarction. Am 7 Cardiol 1982;50:223-9.

19 Marchlinski FE, Buxton AE Waxman $\mathrm{HL}$, Josephson ME. Identifying patients at risk of sudden death after myocardial infarction: value of the response to programmed stimulation, degree of death after myocardial infarction: value of the response to programmed stimulation, degree of ventricular ectopic

20 Treese N, Pop T, Meinertz T, et al. Prognostic significance of repetitive ventricular response in chronic coronary artery disease. Eur Heart 7 1985;6:594-601.

21 Denniss AR, Baaijens $\mathrm{H}$, Cody DV, et al. Value of programmed stimulation and exercise testing in predicting one year mortality after acute myocardial infarction. Am $\mathcal{F}$ Cardiol 1985;56:213-20

22 Breithardt G, Schwarzmaier J, Borggrefe K, Haerten K, Seipel L. Prognostic significance of late ventricular potentials after acute myocardial infarction. Eur Heart $\mathcal{f}$ 1983;4:487-95.

\title{
Hearing and memory in anaesthetised patients
}

The past year or two has seen an increase in medicolegal interest in awareness during anaesthesia. Many legal actions are said to be expected, notably from women who claim they were conscious and able to remember events during general anaesthesia for caesarean section. ' Last year was also the 100th anniversary of the publication of the first scientific study on memory by Ebbinghaus. He found that the capacity of what is now called short term memory is limited to about seven syllables, which, unless transferred to long term memory, persist with decreasing intensity in consciousness until pushed out of awareness by succeeding events. ${ }^{2}$ Only a very small amount of information which evokes a neural response will be stored in the long term memory. Information held in long term memory is wholly unconscious: we become aware of what is there only by transferring small proportions of it into conscious memory. Furthermore, some information stored in long term memory probably cannot be retrieved into working memory. Recent research on hearing and registration in long term memory during general anaesthesia is relevant to the medicolegal problem, and this is an appropriate time to discuss this subject.

As the depth of a general anaesthetic is increased the patient's state changes: from, firstly, conscious awareness with normal recall from long term memory to, secondly, conscious awareness with grossly impaired recall of perioperative events to, thirdly, urconscious awareness, where some stimuli perceived by the brain may be stored in the long term memory but do not subsequently enter consciousness. Finally, perception of stimuli by the brain is severely attenuated, and registration in both short term and long term memory is ablated.

At present the anaesthetist's main source of information on the depth of anaesthesia is the patient's somatic and autonomic responses to surgical stimuli. These responses are modified by neuromuscular blocking drugs and drugs affecting the autonomic nervous system (for example, anaesthetic agents and drugs acting on the cardiovascular system). The presence or absence of these responses does not, however, correlate with conscious awareness ${ }^{3}$ and they are inadequate indicators of a satisfactory depth of anaesthesia. Anaesthetic agents also have amnesic effects, as do drugs such as diazepam, hyoscine, ${ }^{4}$ and lorazepam, which are used perioperatively but which have little effect on conscious awareness.

Two questions need to be addressed. Firstly, is conscious awareness during anaesthesia a frequent event but one which is rarely recalled because of the amnesic effects of perioperative drugs? Secondly, can the depth of anaesthesia be measured objectively so as to eliminate the likelihood of either conscious or unconscious awareness?

The possibility that very light general anaesthesia might exert an important effect on memory was suggested by 
Tunstall. ${ }^{5}$ His patients, lightly anaesthetised and paralysed for obstetric procedures, responded to complex verbal commands by moving a forearm isolated by a tourniquet from the effects of the neuromuscular blocking drug. Postoperatively none of the patients could recollect moving the limb, the discomfort of intubation, or the pain of surgery. In a later study during light anaesthesia there was no convincing evidence of a hand movement in response to command, but movements did occur in response to the noxious stimuli of intubation or surgery. ${ }^{6}$ This might imply a slightly deeper level of anaesthesia than in the previous study-yet these patients did recognise postoperatively words from a list that had been played to them through headphones during the anaesthetic. Bennett et al presented further evidence that processing and storage of auditory information in long term memory may occur frequently in anaesthetised patients. ${ }^{7}$ During general anaesthesia and surgery patients were given information through headphones. The control group "heard" operating room sounds, whereas the test group "heard" a tape which included the instruction that after the operation the patient would recognise the speaker's voice and on doing so would touch his or her ear. A significant number of the test group touched their ears despite being completely amnesic for the intraoperative spoken suggestion even under hypnotic regression. This is an example of unconscious awareness, where high level stimuli are processed by the brain, stored in subconscious memory, may not be retrieved into working memory, but may subsequently influence behaviour. ${ }^{89}$

Possibly, therefore, if an anaesthetised patient hears adverse comments they may be retained in unconscious long term memory, and though inaccessible to postoperative conscious recall, may unfavourably influence subsequent behaviour or convalescence. Solutions might include blocking the ears or playing tapes of favourable comments. Another possibility is that deepening the anaesthesia might itself block this pathway. The development of techniques to monitor the depth of anaesthesia in paralysed patients provides the means both of investigating this possibility and of ensuring that the patients are not so lightly anaesthetised that they have either conscious or subconscious awareness of painful or frightening events.

Detailed study of the function of the auditory pathway during anaesthesia may prove to be a useful technique for measuring the depth of anaesthesia. Sokoloff used radiolabelled 2-deoxyglucose to show that the auditory pathway, and in particular the inferior colliculus, is the most metabolically active part of the conscious brain. ${ }^{10}$ The technique used in conscious man is sufficiently discriminating to show that auditory stimulation by language produces a quite different pattern of regional cortical activation from that produced by music." ${ }^{11}$ This technique has potential for exploring the function of the brain in high level information processing, but it has yet to be applied in anaesthetised man. Nevertheless, studies in animals have shown that different anaesthetics produce quite different effects on the metabolism of different parts of the brain. ${ }^{2-15}$

These effects on regional cerebral metabolic activity in animals can now be correlated with the effects of anaesthetics on regional electrical activity of the brain in man. This is assessed from potentials evoked in the electroencephalogram by stimulation of somatic, visual, or auditory pathways. ${ }^{16}$ The auditory pathway is of particular interest for three reasons: it continues to function during certain stages of general anaesthesia; it has an exceptionally high metabolic activity, which is reduced by most of the anaesthetics so fano studied; and the auditory evoked response has a characteristic wave pattern generated by a variety of relay stations in wel $\mathbb{B}$ defined anatomical structures of the brain stem and cortex. ${ }^{17}$

Recent research in patients shows a clear cut, dose related effect of a range of different anaesthetics, particularly on the latency and amplitude of the cortical part of the auditory evoked response. ${ }^{19-23}$ Furthermore, while the volatile anaes thetics halothane, enflurane, and isoflurane and the intra? venous barbiturates thiopentone (M F M James, personat: communication) and methohexitone affect both the brain? stem as well as the cortical part of the auditory evokede response ${ }^{24}$ the intravenous anaesthetics alphaxalone-alpha $\overline{\bar{v}}$. dolone (Althesin), ${ }^{21}$ etomidate, ${ }^{22}$ the opioid fentanyl, ${ }^{2526}$ and nitrous oxide ${ }^{27}$ attenuate the amplitude of cortical waves but have no effect on the brain stem waves. This sparing of electrical activity in the brain stem by Althesin and etomidate is reflected by the lack of effect on the metabolism in the hind brain up to the level of the inferior colliculus (R A Hawkins, personal communication).$^{28}$ Similarly, sufentanil, an ana-3. logue of fentanyl, does not affect the metabolism of thri inferior colliculus, but reduces the metabolism of the mediafo geniculate and auditory cortex. ${ }^{29}$ Ketamine spares the metais bolism of the auditory pathway up to the inferior colliculus, $\stackrel{1,0}{-}$ but no satisfactory studies in man have been reported on thei effect of this agent on the auditory evoked response. $\stackrel{300}{\longrightarrow}$

Thus some anaesthetic agents spare the brain stem part of the auditory evoked response but there is a universal depressant effect on the cortical part. The dose of drugs needed to suppress completely the auditory evoked response at the primary auditory cortex can now be established. We have shown in man that the early cortical waves are com-o pletely suppressed by intravenous anaesthetics and by any of the three volatile anaesthetics at doses equivalent to the MACo value-that is, the minimum alveolar concentration of gaseous anaesthetics in air required to suppress the response⿳⺈⿴囗十一, to a surgical stimulus in half the patients. By combining 8 psychological and evoked response techniques it now be $\overrightarrow{\overrightarrow{0}}$ comes possible to test the hypothesis that unconscious transfer of verbal information into long term memory may be blocked at concentrations of anaesthetic that block the evoked response at certain parts of the auditory corticals pathway. In this way it may be possible not only to detects conscious awareness but also to establish if there is a dose of aj particular anaesthetic that will prevent the patient from? storing any auditory information during anaesthesia.

Until this research has been done anaesthetists should, perhaps, revise their thinking about current concepts of depth of anaesthesia and should assume that any anaesthetised 0 patient is capable of retaining verbal and other high leve inputs in long term memory. The development for clinical use of a technique to monitor the auditory evoked response would allow the anaesthetist to maintain the depth of anaesthesia at a level where conscious and unconscious awareness is ablated. This should make awareness undefe anaesthesia of historic interest only-in both clinical ande्ष medicolegal terms.

University of Leeds, and MRC Scientific Staff,

Division of Anaesthesia, Clinical Research Centre, Harrow, Middlesex HAl 3UJ

Department of Anaesthetics,

Northwick Park Hospital,

Harrow, Middlesex HAl 3UJ

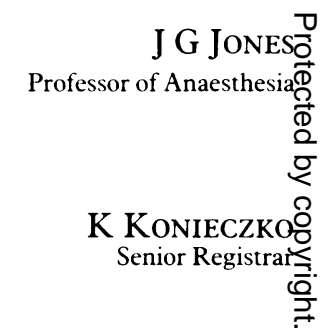


1 Miles T. Women rush to sue over childbirth operations. Sunday Times $1985 \mathrm{Dec} 29: 3(\mathrm{col} 1)$ ). 2 Slamecka NJ. Ebbinghaus: some associations. J Exp Psychol (Leam Mem Cogn) 1985;11:414-35. 3 Hug CC. Lipid solubility, pharmacokinetics and the EEG; are you better off today than you were four years ago? Anesthesiology 1985;62:221-6.

4 Frith CD, Richardson JTE, Samuel M, Crow TJ, McKenna PJ. The effects of intravenous diazepam and hyoscine upon human memory. $Q f$ Exp Psychol $(A)$ 1984;36:133-44.

5 Tunstall ME. Detecting wakefulness during general anaesthesia for caesarean section. $\mathrm{Br} \mathrm{Med} \mathcal{J}$ $1977 ; \mathrm{i}: 1321$

6 Millar K, Watkinson

1982;26:585-94. Anaesth 1985;57:174-9.

8 Dixon NF. The conscious-unconscious interface: contributions to an understanding. Archiv für Psychologic (Bonn) 1983;135:55-66.

9 Dixon NF. Preconscious processing. Chichester: John Wiley and Sons, 1981

10 Sokoloff $\mathrm{L}$. Localization of functional activity in the central nervous system by measurement of glucose utilization with radioactive deoxyglucose. F Cereb Blood Flow Metab 1981;1:7-36.

11 Phelps ME, Mazziotta JC, Huang S-C. Study of cerebral function with position computed tomography. 7 Cereb Blood Flow Metab 1982;2:113-62.

12 Lu DM, Davis DW, Mans AM, Hawkins RA. Regional glucose utilization determined autoradiographically in brief experiments with $2 \cdot{ }^{1+} \mathrm{C}$ glucose. Am J Physiol 1983;245:428-38.

13 Hawkins RA, Biebuyck JF. Regional brain function during graded halothane anesthesia. In: Fink BR, ed. Molecular mechanisms of anesthesia. (Progress in anesthesiologv. Vol 2.) New York: Raven Press, 1980:145-56.

14 Crosby G, Crane AM, Sokoloff L. Local changes in cerebral glucose utilization during ketamine anesthesia. Anesthesiologv 1982;56:437-43.

15 Herkenham $M$. Anesthetics and the habenular-interpeduncular system: selective sparing of metabolic activity. Brain Res 1981;210:461-6.

16 Jones JG, Heneghan $\mathrm{CPH}$, Thornton $\mathrm{C}$. Functional assessment of the normal brain during general anaesthesia. In: Kaufman L, ed. Anaesthesia review (3). Edinburgh: Livingstone, 1985:83-98.
17 Dorfman LJ. Sensory evoked potentials. Annu Rev Med 1983;34:473-89.

18 Woods DL, Hillyard SA, Hansen JC. Event-related brain potentials reveal similar attentional mechanisms during selective listening and shadowing.J Exp Psychol (Hum Percept) 1984;10: $761-77$.

19 Thornton C, Catley DM, Jordan C, Lehane JR, Royston D, Jones JG. Enflurane anaesthesia causes graded changes in the brainstem and early cortical auditory evoked response in man. $\mathrm{Br} \mathcal{J}$ Anaesth 1983;55:479-86.

20 Thornton C, Heneghan CPH, James MFM, Jones JG. Effects of halothane and enflurane with controlled ventilation on auditory evoked potentials. Br f Anaesth 1984;56:315-23.

21 Thornton C, Heneghan CPH, Navaratnarajah M, Jones JG. Selective effect of Althesin on the auditory evoked response in man. Br 7 Anaesth 1986:58:422-7.

22 Thornton C, Heneghan CPH, Navaratnarajah M. Bateman PE, Jones JG. The effect of etomidate on the auditory evoked response. Br f Anaesth 1985;57:554-61.

23 Sebel PS, Ingram DA, Flynn PJ, Rutherford CP, Rogers H. Evoked potentials during isoflurane anacsthesia. Br J Anaesth 1985;57:340P.

24 Kriss A, Prasher DK, Pratt RTC. Brainstem and middle latency auditory EP's evoked during unilateral electroconvulsion therapy (ECT). In: Nodar RH, Barber C, eds. Second intermational evoked potentials symposium. Vol 2. Boston: Butterworth, 1984:582-8.

25 Samra SK, Lilly DJ, Rush NL, Kirsh MM. Fentanyl anesthesia and human brain-stem auditory evoked potentials. Anesthesiology 1984;61:261-5.

26 Velasco M, Velasco F, Castaneda R, Sanchez R. Effect of fentanyl and naloxone on human somatic and auditory evoked potential components. Neuropharmacologv 1984;23:359-66.

27 Lader MW, Norris $\mathbf{H}$. Effect of nitrous oxide on the auditory evoked response in man. Nature 1968;218:1081-2

28 Davis DW, Hawkins RA, Mans AM, Hibbard LS, Biebuyck JF. Regional cerebral glucose utilization during anesthesia. Anesthesiology 1984;61:362-8.

29 Young ML, Smith DS, Greenberg J, Reivich M, Harp JR. Effects of sufentanil on regional cerebral glucose ultilization in rats. Anesthesiologv 1984;61:564-8.

30 Pacelli GD, Culen BF, Starr A. Effects of thiopental and ketamine on middle latency auditory evoked responses. Anesthesiology 1983;59:366.

\section{Incompetence in medical practice}

Competence in medicine is recognisable and incompetence even more so. Each of us is guilty of occasional lapses of judgment and skill, which we bitterly regret and resolve will not occur again - as far as it is in our power. Provided that the outcome of such a lapse is not wickedly disastrous it may almost be forgiven since "to err is human." Even when the outcome causes harm the victim might receive at least partial redress through pursuit of a claim against the doctor backed by his defence society and his employers or employing agency. Within limits well tried mechanisms work reasonably, though they are often cumbersome and slow, leaving the aggrieved claimant even more bitter and hurt than he might reasonably be when he believes that he has been the victim of some form of medical laxity or indifference.

These isolated failures are one problem; the other-more difficult and unacknowledged by the profession-is the doctor who almost constantly falls below accepted standards of practice. Most often this behaviour is due to ignorance of what he ought to know and what he ought to do in given circumstances. He does not know or understand the generally accepted standards of his peers in practice.

Standards are defined in general terms at the time of qualification: all British universities follow the curriculum and forms of assessment suggested by the General Medical Council in its recommendations on basic medical education. As with any system devised to attempt to show that a person is fit to continue to the next phase of training and education, however, the filter lets some through who, in the light of later experience, ought not to have been passed. This small minority should be on the conscience of the profession, for they may drift on; and the later system rarely picks them up or applies remedial action. The standards required of a preregistration house officer at the end of his year in the grade are still too vaguely drawn by the GMC. The responsibility for supervision of the year resides with the universities; they have improved the quality of the experience of preregistration house officers, but much remains to be done for the individuals in post.
The final responsibility falls on the consultants who have preregistration house officers working for them. They need fuller and firmer guidance from the GMC on what is required of them, perhaps backed by inspections at intervals to reinforce those already carried out by the universities. The dual system of inspection of posts by a national body as well as a local one has been shown to be of value for other training posts. It should also be made easier for consultants to report suspected incompetence in their preregistration house officers so that remedial action could be taken. There are mechanisms for this to be done at present, but they are hard to put into action because of matters of contracts and the legal rights of doctors who have served for a few months. The certificate of satisfactory completion of preregistration service sent to the GMC has come to mean only that the person has served for a minimum period in office. Once that is passed he is deemed legally to have been satisfactory, for if he had been unsatisfactory his contract would have been terminated. Not surprisingly, few consultants are willing to go that far. They recognise that their estimate of another person's competence may be wrong, especially if it has to be made over only a few weeks. The grass grows under everyone's feet until it may be too late to do anything effective.

The same may happen in the training grades of senior house officer and registrar. For various reasons, some contractual and some personal, consultants find it scarcely possible to do much about the poorly performing trainee doctor except to restrict his areas of work and supervise him closely until he moves on and becomes someone else's problem. Very few consultants are willing to damn a junior doctor's career utterly in a written reference. Even if they are sure that they should do so they may well then be faced with an unpleasant, possibly legal, inquiry and have to justify their criticisms. Supplying chapter and verse for these can be nearly impossible long after the events in question-we do not maintain dossiers on one another. And junior doctors move from region to region, so that an individual's ill starred 